\title{
INTRODUCTORY APPROACH TO ECO-HYDROLOGICAL URBANISM: THE ADAPTIVE REUSE OF PEMEX FORMER REFINERY IN REYNOSA, MEXICO
}

\author{
JOSE ANTONIO HERRERA \& ANGELA LOMBARDI \\ The University of Texas at San Antonio - School of Architecture, Construction, and Planning, USA
}

\begin{abstract}
PEMEX Urban Park is an urban regeneration project focused on the remediation and reclamation of PEMEX's brownfield and the adjacent natural lagoon 'Laguna La Escondida' located in the city of Reynosa, Tamaulipas, Mexico. The 65-hectare brownfield is strategically located within the urban center, one of the causes of high levels of air and water pollutants in the city. Historically, the presence of the oil refinery generated dystopic neighbourhoods, some with no access to public spaces, others with inadequate conditions for any type of sustainable community engagement. The natural lagoon, the 'Laguna La Escondida', is a 152-hectare body of water, contaminated by toxic metals and chemicals produced by the refinery and the city's uncontrolled rapid growth. Although contaminated, the lagoon is an essential resource for many local floras and migrating species of fauna. This study includes a thorough analysis of comparable precedents of industrial heritage sites, their associated values and strategies of transformation of polluted landscapes, demonstrating the needs of a broader urban-hydro-ecological approach, emerging from the desire to revive and reintegrate nature into the city. Site analysis and case studies also highlight the important role of culture, of the history embedded in the place, as well as the communities interlinked with the oil refinery. The project, implementing the transformation of PEMEX oil refinery into an urban park, will keep the refinery infrastructure untouched as a memory of the past, acting as a catalyst for eco-socio-cultural activities, providing the community with a place to reconnect as a civic society. The proposal enhances the inherent values of the site, such as history, culture and nature. While purification of water is the focus of this new urban-hydro-ecological proposal, the research suggests alternative remediation strategies that will reverse the damage without compromising future generations' wellbeing. Phytoremediation and rhizo-filtration strategies are analysed as a technique to clean the toxins and heavy metals from the contaminated soil and water. The bioremediation of the lagoon would increase water-quality and reinstate the biodiversity. PEMEX Urban Park envisions an urban eco-hydrological future of the area and re-imagine it as a social condenser in response to capitalism as a form of urbanization.

Keywords: Industrial adaptive reuse, Water heritage, Eco-hydrological urbanism, Environmental remediation and reclamation, Degraded landscapes, PEMEX Urban Park, Ecology.
\end{abstract}

\section{INTRODUCTION}

The 65 hectares of a former oil refinery site located in the city of Reynosa, Mexico, in 2017, was donated by PEMEX Petroleos Mexicanos to the state of Tamaulipas and became public property [1]. With its industrial remnants, the vacant site is highly strategic because of its geographical location and its historical, cultural, and environmental roles. The industrial site (Fig. 1) is located 1.35 miles from the historic core of the city. The whole area was originally part of the city's public farmlands - los ejidos de la villa de Reynosa [2]. Before PEMEX's oil refinery occupation, the site was still public property occupied by military barracks. Adjacent to the site, a natural lagoon, the Laguna 'La Escondida' is a 152-hectare contaminated body of water. Although contaminated by toxic metals and chemicals produced by the refinery and by the city's uncontrolled rapid growth, the lagoon is still an essential resource for many local floras and migrating species of fauna. The presence of the oil refinery generated a new economy and a modern city around it. During the refinery operation period, surrounding 


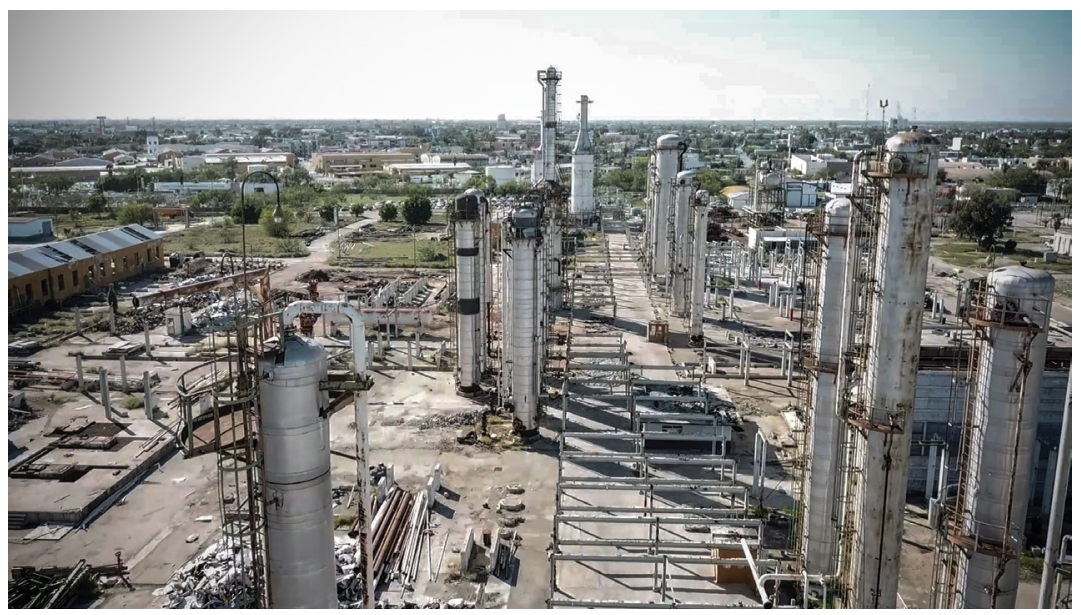

Figure 1: Existing condition of the dismissed industrial apparatus.

mixed-use residential neighbourhoods were constructed, generating dystopic urban conditions with high levels of air and water pollution and lack of walkable and public spaces. Air pollutants, such as carbon monoxide, nitrogen oxides, sulfur, and dioxide, generated by PEMEX activities, were flowing across, polluting, both sides of the border [3]. Although the dystopic character of the neighbourhoods around PEMEX, paradoxically, the mixed-income character of such areas features a strong sense of place, in which the refinery and its tall infrastructure plays the role of historic landmark/monument and meeting point for the residents. The mixed-income character of the surrounding neighbourhoods adds multiple values to the refinery's degraded land, having the potential to become a democratic space in the city, due to the physical connection of the various social-economic groups. These values give an opportunity for a new urban eco-socio-cultural future as an urban park. Urban and environmental regenerations are needed to use the vast industrial land area as a healthy and safe place to inhabit. Regeneration through alternative environmental strategies of bioremediation and reclamation of degraded landscapes are proposed to clean the by-products of the refinery.

The regeneration proposal's goal cannot rely only on ameliorating the contaminated land of the former refinery and transforming it to serve the public. Through remediation and reclamation as a public park, PEMEX's former oil refinery has the potential to become a catalyst of new social forms towards a more equitable civic society, the PEMEX Urban Park. The park will play the role of social condenser, equitable for all users [4]. An urban hydro-ecological paradigm emerges from the use of nature to reverse the site's decay and pollution, reviving and reintegrating nature into the reused industrial site to support a civic society evolving towards equality. The radical nature of such a new urban hydro-ecological approach will include the lagoon's water as an essential component of the site's ecosystem - and through bioremediation, water will return to its life source role. The overall focus of this extensive multidisciplinary study aims to create sustainable and equitable strategies for the adaptive reuse of industrial sites, water heritage, and its related ecosystems and ecologies. It proposes an evolutionary socio-cultural framework for the civic society of the Anthropocene era. The goal of this paper is to provide a framework for future rehabilitation of the dismissed industrial site of Reynosa's former PEMEX oil refinery. 


\section{METHODOLOGY}

This study aims to create an urban regeneration proposal for the former PEMEX oil refinery through alternative reclamation and remediation strategies. The overall goal is achieved by identifying various objectives and creating a methodological framework for polluted industrial sites' transformation (Fig. 2). One of the research objectives is analyzing and interpreting the design strategies and environmental cleaning techniques utilized in similar comparable cases through a literature review.

A second research objective is identifying challenges and needs to undertake sustainable reuse of the PEMEX site, considering the inherited values of the site.

Environmental challenges' assessment and design strategies emerge from the desire to re-incorporate nature into the sites to outline new urban futures such as eco-hydrological urbanism. Site value analysis demonstrates the efficacy of the strategies of reclamation and remediation. Alternative environmental cleaning strategies applied in polluted sites are identified as instruments to re-incorporate nature into the sites and achieve a successful urban regeneration proposal.

The literature review provides an overview of historical and contemporary precedents of the transformation of degraded industrial landscapes and adopted site transformation strategies.

Particularly relevant to our study is the historical transformation of the Back-Bay Fens' degraded landscape in Boston, MA, the Parc des Buttes-Chaumont in Paris, and a limestone quarry in Yucatan, Mexico.

In Seattle, Gas Works Park represents one of the earliest post-industrial US sites transformed into a public park in 1971-1976. Designed by Richard Haag and Associates, the park is a relevant 20th-century case of transformation through remediation and reclamation.

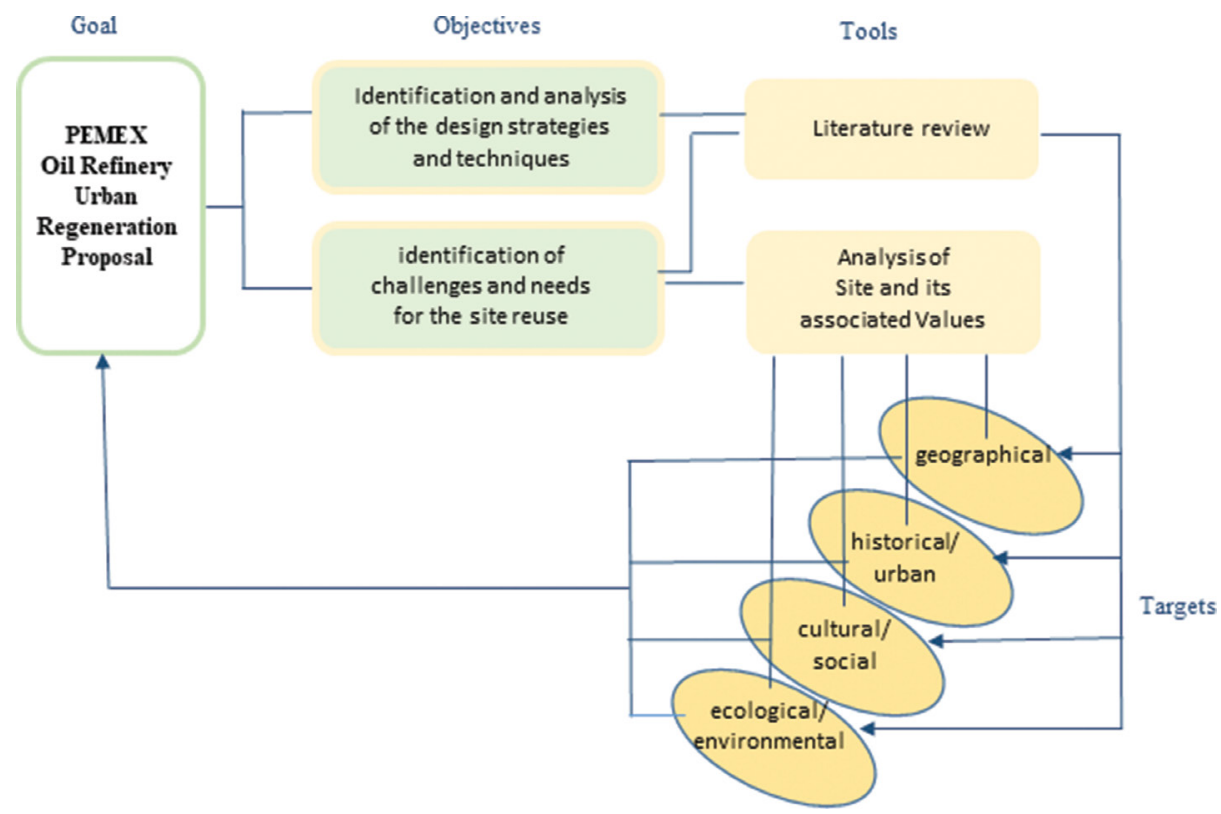

Figure 2: Methodology diagram for this study, representing the framework for the urban regeneration proposal. 
Parc de la Villette in Paris, France, is a former industrial site in the city's outskirts. It has been entirely transformed by the visionary project of OMA and Rem Koolhaas in 1982-1983. The project is based on a conceptual approach on which the area's spatial organization is reorganized by exploring the idea of the strip as a strategy for the collectivization of activities and the condensation of society.

Jardin Natura, Parque Bicentenario in Azcapotzalco Mexico, is a park created from the 55-hectare former PEMEX oil refinery in the outskirts of Mexico City, designed by the recipient of the Sir. Geoffrey Jellicoe award landscape architect Mario Schjetnan and his Grupo de Diseño Urbano. The project was carried out by high level Mexican academic institutions and sponsored by Instituto Mexicano del Petroleo. It is definitively an emblematic case of remediation and reclamation.

\section{ADAPTIVE REUSE OF WASTE LANDSCAPES IS NOT A NEW APPROACH!}

An analysis of historical precedents shows that degraded landscapes have been addressed since the 19th century. Featuring, however, an aesthetic model and philosophical framework that were definitively the products of its time: the waste is made invisible, the industrial character is hidden rather than considering the industrial apparatus and the waste of production as part of the urban landscape.

Paramount of wasted landscapes' rescue is the 19th-century Parc des Buttes-Chaumont, located in the north-east side of Paris, France, and completed in 1867 [3]. The park featured a quarry transformed into a public landscape. The project was designed by Jean-Charles Adolphe Alphand (1817-1891), the creator of all the major parks supported by Napoleon III as part of his political agenda. The park engages with its historical, geological, cultural and industrial narratives, showcasing a new type of landscape experience, expressing the site's modern nature and its industrial character [5].

Another pivotal project is the 1880s Back-Bay Fens landscape completed by Frederick Law Olmsted (1822-1903) and Charles Eliot (1859-1897) in Boston, MA. It is considered a benchmark for land reclamation bringing science and engineering together with the design [3]. The intervention consisted of transforming a smelly tidal creek and swamp into a winding creek and wetland. The design and engineering turned the site affected by the machine into a place where ecological processes nurtured the land. At the same time, social-access was made possible.

Another relevant project of degraded landscapes is the reclamation of a limestone quarry through re-appropriation by nature in Merida Yucatan, Mexico in 1990 by Materiales Anillo Periferico Company (MAPSA.) The owners decided to convert the quarry after a long history of abuse by the mining activities. The in situ reclamation method focuses on the use of tropical and subtropical agroecosystems local to the region, starting by planting 12 hectares of a tree-grass mixture of Leucaena leucocephala (huaxin) and Cynodon nlemfuensis (star grass). Nature was able to reconquer the site effectively; by 2000, the tree survival rate resulted in being higher than $90 \%$. In the year of 2000 three more hectares were planted [6].

\section{HISTORY: GAS WORK PARK IN SEATTLE - LAYERS OF HISTORY REVEALED}

Gas Works Park in Seattle serves as precedent for being one of the earliest post-industrial sites transformed, during the 20th century, into a public park through remediation and reclamation. Gas Work Park's location is on a coal and oil gasification plant site that ceased operation in 1956. During operation, many types of wastes, including coal, tar, and oil, 


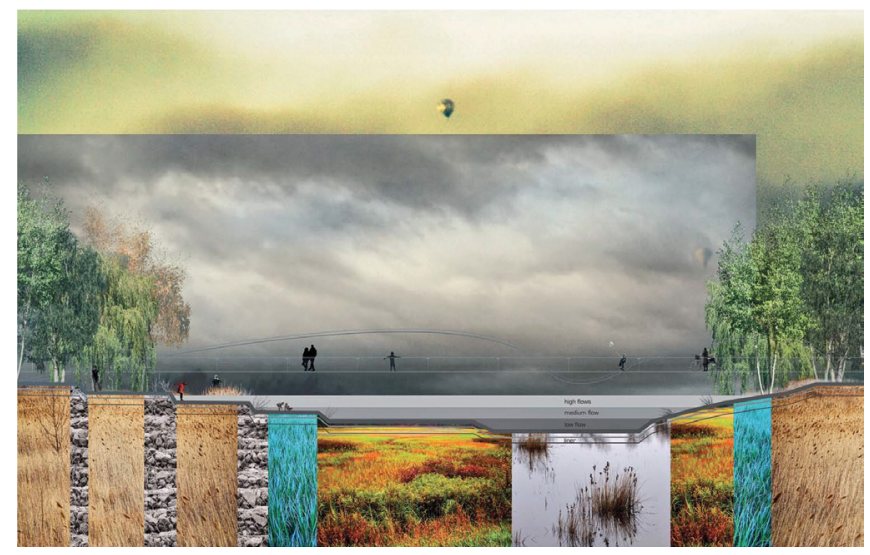

Figure 3: Tera Hartfield's subversive cartography effectively illustrates the ecological and cultural histories and narratives in this representation of Gas Work Park's 'thick section' (Source: Way, 2013. p.37).

accumulated in-situ. The park was created in the 1970s, designed by Richard Haag and Associates (1966-2016), using as a conceptual reference Trawsfynydd Power Station in the UK, a landscape of power and industry [3].

The park design addresses the adaptive reuse of waste landscapes, ameliorating contaminated land, and creating a place that serves the public [3]. Haag's narrative is highly innovative reading through the land in conjunction with that of the structures. The designer uses the term 'thick section,' acknowledging the complex layers of history revealed in section (Fig. 3). The project engages the complexities and narratives of the existing landscape learning from its history, while it emphasizes the potential power of landscape narratives, envisioning potential futures. The project also addresses the links between industry, pollution, and health, adopting the radical idea to conserve the soil and treat the toxins in-situ. Designers encountered difficulties convincing officials and citizens of the importance of retaining part of the industrial apparatus in-situ as part of the history of the place and providing a space of unique, evocative beauty, showcasing - at the same time - the industrialization and its effects of modernization. The park's creation was associated with numerous challenges and constraints, since, in 1986, the park's soil appeared to be still contaminated with polynuclear aromatic hydrocarbons, volatile organic compounds, trace metals, and cyanide. Analysis of water samples from a network of observation wells in the park indicated in the 1990s that these compounds were still present in the groundwater [8].

\section{A PHILOSOPHICAL APPROACH TO PROGRAMMING AND SPATIAL ORGANIZATION OF LARGE SITES: LEARNING FROM PARC DE LA VILLETTE IN PARIS}

Parc de la Villette was an international competition held to design the park of the 21 st century on a former vacant industrial site. The goal was simple: "comment trouver [...] un parc fédérateur, qui puisse permettre aux gens de se rencontrer?" ('how to find [...] a cohesive unifying park, which could allow people to meet?') [5]. For Koolhaas, the essence of Parc de 
la Villette was the transformation of society through a 'social condenser', which is defined by Rem Koolhaas as 'layering upon vacant terrain to encourage dynamic coexistence of activities and to generate through their interference, unprecedented events' [4].

The term social condenser was coined by Russian-constructivist Ivan Leonidov (19021959 ) in 1920 to construct society parallel to evolving social forms of new life. The social condenser's philosophical approach is focused on condensing and reconstructing society through the collectivization of activities. To design a vast area's programming and spatial organization, Koolhaas used as a reference the Berlin wall, being an example of void or strip to imagine nothingness - realizing the potential flexibility of the no man's land. Koolhaas' project embraces two opposite concepts and organizes elements of a strip (like Berlin wall), creating ribbons of indeterminate programming, using the tactic of dividing the strip into squares, allowing for a sequence of events to take place. Such a philosophical approach is interdependent of the grounding metabolism attracted by the place's new eco-cultural values.

The idea of keeping the industrial apparatus as a landmark contrasting the Mexican sky is suggested by the atmospheres provided by the Gas Work Park project in Seattle. The social condenser, the strip, and the vast area's spatial organization, are styled by Koolhaas. The use of the strip is also present in Schjetnan's Jardin Natura, Parque Bicentenario project (Fig. 4 \& 5). The strip's approach in Jardin Natura is applied to accommodate the nature of diverse ecologies. Complementary to the spatial organization of nature, the strip dictates the functionality of the site. Nature's vital role as a powerful tool to reclaim degraded landscapes comes from the Mexican sensitivity towards nature. Mexican landscape architect Mario Schjetnan expresses such sensitivity in his projects, creating different ecologies within vast land areas, allowing visitors to engage in a multi-scale experience of nature. Simultaneously, the nature introduced into the site reverses hydrological and geological damages caused by industrial activities.

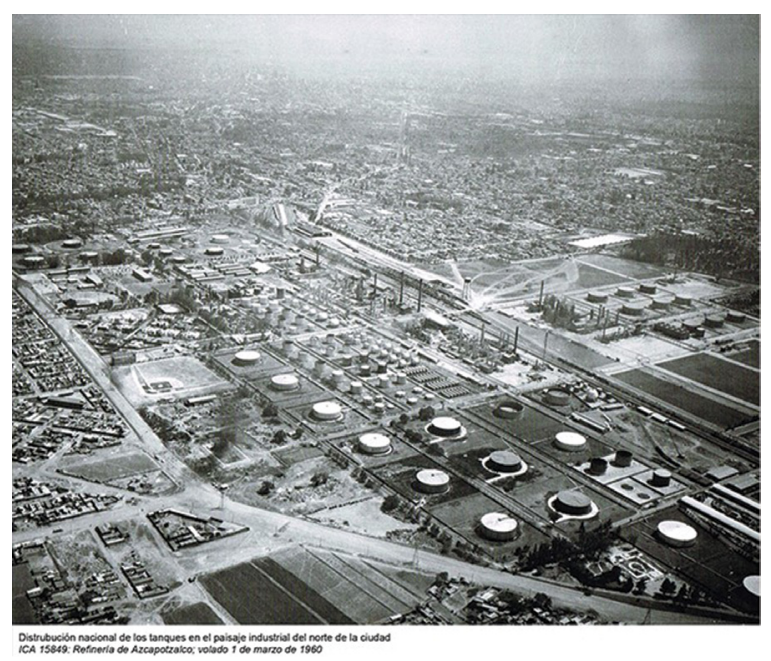

Figure 4: '18 Marzo' Refinery in Azcapotzalco Mexico in 1980s and Mario Schjetnan's master plan for Jardin Natura, Parque Bicentenario (Source: http:/gdu.com.mx/gdu/ portfolio/jardin-). 


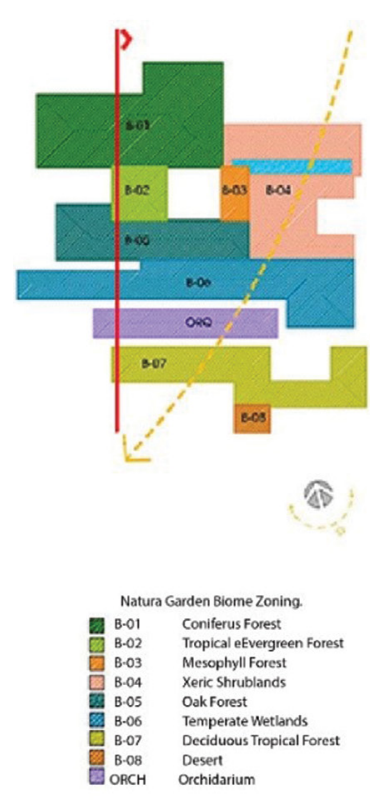

SITE PLAN

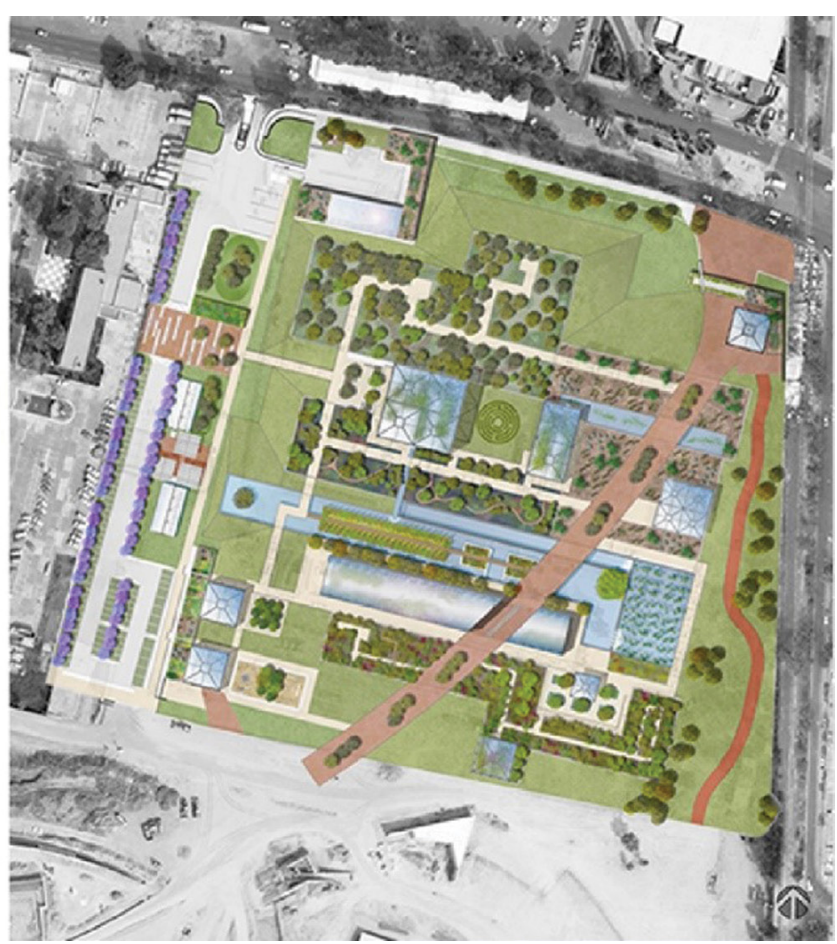

Figure 5: Mario Schjetnan's master plan for Jardin Natura, Parque Bicentenario. (Source: http://gdu.com.mx/gdu/portfolio/jardin-natura-parque-bicentenario/).

\section{NATURE: UNCOVERED SCENARIOS FOR PEMEX FORMER REFINERIES; THE CASE OF PARQUE BICENTENARIO IN MEXICO CITY}

The conversion of PEMEX's former refinery into Jardin Natura, Parque Bicentenario, is a pivotal recovery of waste landscape in Mexico, led by Mario Schjetnan Garduño and his Grupo de Diseño Urbano. This multiple-award project is paramount of an ecological approach to the urban and non-urban landscapes. It incorporates symbolic elements of the nation's cultural identity and its relationship with nature by creating a microcosmos - condensed in one park - replicating the eight climatic ecosystems of Mexico. Once, one of the highest causes of pollution in the city capital, the refinery ' 18 de Marzo', is located in Azcapotzalco in the northern part of Mexico City. It shut down in 1988 as part of Mexico's process to relocate polluting industries outside the city. The federal government donated 55 hectares to build a public park - the Parque Bicentenario [12]. PEMEX was in charge of the environmental remediation of the site, and in 2006, the Instituto Mexicano del Petroleo carried out the first formal characterization of the site.

The site characterization allowed to determine the ground's specific condition, identifying seven different contaminated zones, their contaminants' concentration, and their depth. Remediation strategies were organized in two phases and divided into four zones featuring different levels of contamination. Zone 1 did not need remediation due to the low levels of contamination established by the environmental norms. Phase 1 included the approval of the technologies to be applied to remediate the refinery, based on the Secretariat of Environment and Natural Resources SEMARNAT in November 2006 [12]. 
In February 2007, the first phase of the remediation began and focused on sample areas of the three zones to be treated (Zones 2, 3 and 4). In-situ bioremediation strategies of the sample areas included the use of treatment cells. They were carried out by the Universidad Autonoma de Puebla, treating 7,951 $\mathrm{m}^{2}$ (85,583 sq. ft.) along with the Instituto Tecnológico Agropecuario de Oaxaca, which treated larger areas for a total of 44,672 $\mathrm{m}^{2}$ (480,845 sq. ft.). In July 2008, the final testing's positive results demonstrated the success of phase one remediation strategies. Phase two applied phase one remediation strategies at a larger scale. The in-situ bioremediation strategies summary of Parque bicentenario is in the table below:

Table 1: Bioremediation strategies.

\begin{tabular}{ll}
\hline & Subheading \\
\hline $\begin{array}{l}\text { Bioremediation } \\
\text { through excava- } \\
\text { tions and extraction }\end{array}$ & $\begin{array}{l}\text { Excavations were carried out to extract the polluted soil and } \\
\text { transported to treatment areas in which the concentration of hy- } \\
\text { drocarbons was reduced adding nutrients and oxygen to the soil it } \\
\text { reduces. } \\
\text { Biopilas }\end{array}$ \\
$\begin{array}{l}\text { On-site decontamination of soil with organic compounds of low } \\
\text { concentration. } \\
\text { Nutrients are added if required to increase the hydrocarbon } \\
\text { degradation }\end{array}$ \\
Creation of holes through excavation on the ground to allow air into \\
the subsoil to volatilize contaminants. This technique was adopted \\
excavating 3,120 holes on site with a depth of 3.5 m (11.48 feet) \\
Process based on injecting oxygen into the soil to increase biologi- \\
cal activity while degrading hydrocarbons \\
Technique consisting on excavating holes of 8 m (26 feet) deep to \\
insert air into the underground water to absorb benzene.
\end{tabular}

Although Schjetnan's landscapes focus on public spaces' reactivation, this is not the main focus in Mexico City's Chapultepec Park [13]. Because of this park's unique characteristics being historically, socially and culturally significant, Schjetnan focuses on the reconnection and remediation of nature, cleaning of ponds and restoring water movement in the streams as an ecological necessity to provide a healthy environment in the core of a mega-city.

\section{CULTURAL SIGNIFICANCE OF ADAPTIVE REUSE OF INDUSTRIAL HERITAGE}

Roseland introduces the concept that 'cultural capital' is 'the product of shared experience through traditions, customs, values, heritage, identity, and history; which represent the cultural and traditional resources of a community' [8]. Industrial heritage builds on the history and identity of a place. It shapes a community's culture and traditions. The longer the industrial apparatus is present in the skyline, the more that industry becomes a symbol to the place, and the more it identifies with the community's cultural image.

Fundidora de Fierro y Acero de Monterrey, S.A. in Monterrey Nuevo Leon, is one of Monterrey's cultural heritage sites. Founded in 1900, the Fundidora was a steel manufacturing business producing non-planar steel like train rails, steel rods, and train wheels. The steel industry brought economic development to the city, providing its workers a wealthier 
lifestyle. The Fundidora became a symbol of prosperity, embodying as well the values created by industrial labourers. It was the main reason for Monterrey's economic development, giving the industrial city international recognition. The industrial apparatus is a reminder of the beginnings of the city and the vision of its founders. Today, the remnants of this industry are part of an adaptive reuse project, Parque Fundidora. The project gives a cultural significance to the industrial heritage site by providing a public space for social interaction. It also adds economic value to the site, due to the recycling of the structures and the adaptation of former industrial buildings into a cultural tourist and local attractions. This adaptation allows for capitalizing. As a form of culture, industrial heritage, and adaptive reuse seem to form a mutualistic relationship.

\section{PEMEX FORMER REFINERY IN REYNOSA: AN ECO-HYDROLOGICAL APPROACH TO DEGRADED LANDSCAPE}

PEMEX Urban Park is envisioned by developing a conceptual framework based on the radical nature of a new urban-ecological paradigm. The 'Eco-Hydrological Urbanism' will be able to impulse the process for the evolution of the civic society towards new ecological futures. The conceptual framework is based on the social grounding metabolism, i.e., the physical configuration of human occupation 'on the ground' to operate as a holistic system, channelling the social condenser's activities through educational experience. Three are the components of the conceptual framework: history, nature, and culture. Concerning history, elements of the industrial apparatus are retained, seeking to voice the site's past, framing them as ruins and place-makers. The industrialized physical context will remain present, will be reused, and reinterpreted within new social-ecological scenarios. Nature: the use of botanical bioremediation strategies addresses the contaminated land of the oil refinery and the lagoon's water. Bioremediation strategies' sub-systems include phytoremediation and rhizo-filtration consisting of a set of technologies which exploits the ability of some plants to absorb, accumulate, metabolize, and volatilize contaminants [9]. Phytoremediation involves the use of plants to decontaminate soils, water, and - consequentially - air. It stabilizes pollutants present in the soil, air, water, and sediments such as heavy metals, radioactive metals, organic compounds, and compounds derived from petroleum. Rhizofiltration is the process in which plants' roots absorb the contaminants from the surrounding polluted waters [10]. Eco-hydrology research links water cycles with the ecological process, displaying the effects of plants on water cycles. Applying botanical bio-remediation strategies requires an extensive analysis of the site (Fig. 6) to identify the contaminants and their quantities. For further development, multidisciplinary collaboration is in progress to develop detailed strategies for remediating the site utilizing the appropriate botanical and biological species to clean the soil and water.

Previous research has proven that using mesquite (Prosopis laevigata) trees allows metabolizing heavy metals. In the mentioned study, the plants hyper accumulate $4,100 \mathrm{mg} /$ $\mathrm{kg}$ of Aluminum (Al), 14,000 mg/kg of Iron (Fe), 1,600 mg/kg of Titanium (Ti), and 2,500 $\mathrm{mg} / \mathrm{kg}$ of Zinc (Zn) over two months [11]. This study can be utilized as a precedent to calculate a tentative timeline for the botanical bio-remediation applied in PEMEX Urban Park. Culture, the remediated landscape will partially turn into contemporary 'ejidos', farmlands for urban community farming. The new farmlands will function as a holistic ecological discourse, serving not only for food production, but also for reconnecting people - and young generations in particular - to the environmental and sustainable food chain and regional food cultural traditions. 


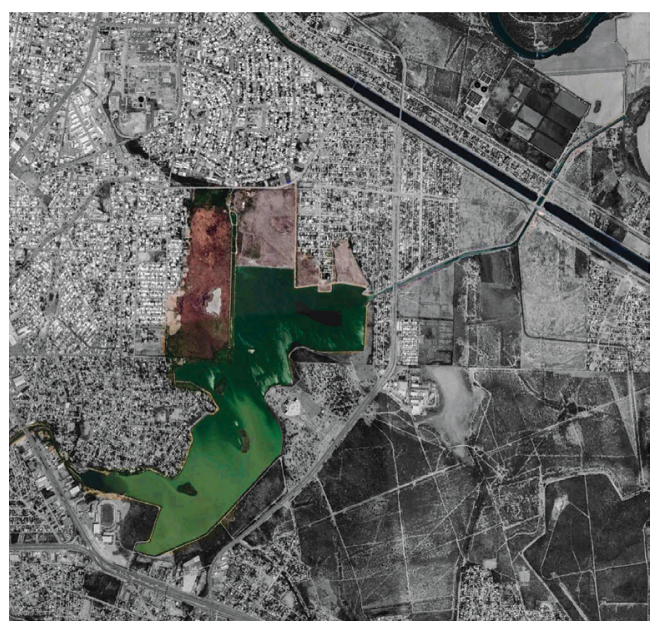

Figure 6: Plan showing the city, the rural land, and the main human-made canals of Reynosa. In dark turquoise is the lagoon 'Laguna la Escondida', in maroon is the former refinery site and the land adjacent to the lagoon, contaminated by the refinery byproducts.

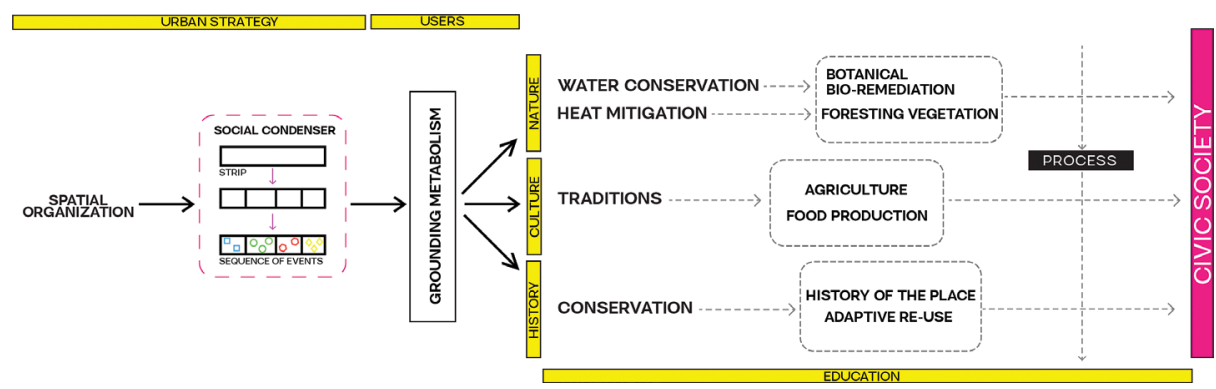

Figure 7: Diagram of the adopted approach towards 'Eco-Hydrological Urbanism.'

The conceptual framework of History, Culture, and Nature, along with its sub-systems and micro-mechanisms of the urban strategy, work together as a hybrid infrastructure through an educational experience (Fig. 7). The educational experience is interconnected and dependent on the site's new spatial organization.

The urban strategy, the new spatial organization, based on the micro-mechanism of the 'strip sequence,' will shape the site of the oil refinery, with indeterminate programming in its vast area (Fig. 8). It will provide a sequence of events to encourage the dynamic coexistence and collectivization of activities, based on the new urban-hydro-ecological paradigm. The sequence of events will work as social catalysts for the new Pemex Urban Park as a 'social condenser' Supporting the development of the civic society. 


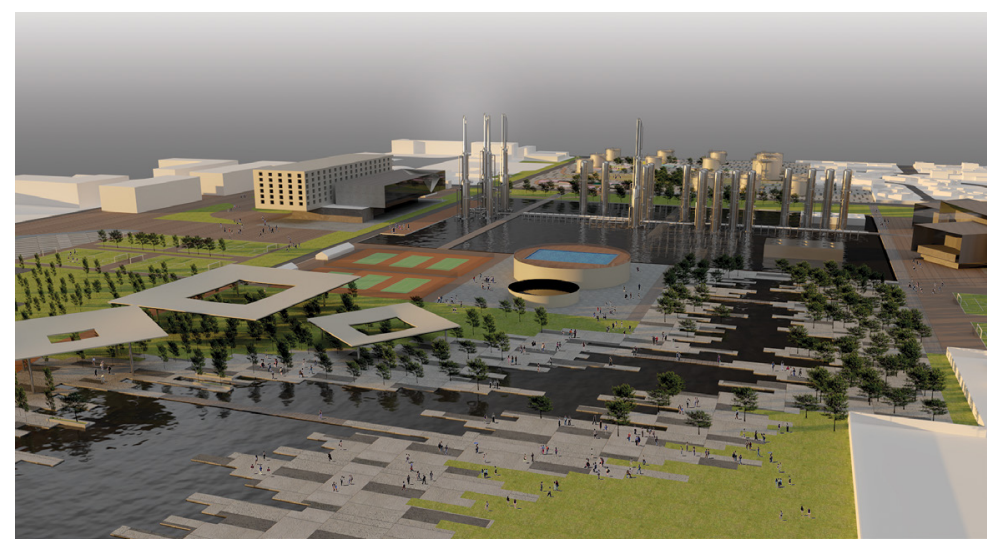

Figure 8: Render of the PEMEX Urban Park featuring the strip spatial organization integrated with the water, nature and the preserved industrial apparatus.

\section{CONCLUSION}

The adaptive reuse of the former refinery in Reynosa highlights the need of adopting a new approach, the 'Eco-Hydrological Urbanism,' because of the intimate interconnection between the Rio Grande River, human-made canals, PEMEX former oil industrial site, the lagoon 'Laguna la Escondidas' water, and the Gulf of Mexico. The analysis of precedent studies on the remediation and reclamation of industrial degraded landscapes emphasize: the vital role of nature in the cleaning strategies; the value of keeping the industrial apparatus untouched as a memory of the past; the need of a conceptual framework focused on the spatial organization of a vast land area; the condensation of society and the collectivization of activities organized through strip elements and the need to provide a place for social interaction for the development of a more equitable civic society. Our proposal adopts, as strategies, nature, history, and culture; PEMEX Urban Park will be paramount of a new eco-hydrological approach. Through academic institutions' involvement, the next phases will entail the detailed design of bioremediation processes and their methods of execution. The essential components for a successful implementation of the PEMEX Urban Park project are the public engagement process. This will include the active engagement of the surrounding population, stakeholders' participation to support the project, and the support of public institutions at local and state levels. Shifting the paradigm to the 'Eco-hydrological Urbanism' requires not only a multidisciplinary academic effort but also the engagement of different representatives, at multiple levels and scales, of the civic society.

\section{ACKNOWLEDGEMENTS}

The authors would like to thank Genesis Eng, colleague and friend, with whom they shared this investigation's beginnings; She is one of the PEMEX Urban Park project proposal authors. Authors want to express their gratitude to Dr. John Murphy, former dean of the College of Architecture, Construction, and Planning, to the Center of Cultural Sustainability at the University of Texas at San Antonio. They both awarded this proposal as a master thesis project in 2019 and encouraged the continuation this research. Author Jose Antonio Herrera expresses his gratitude to his dearest parents, Antonio Herrera and Leticia Flores, for all their support and love; to his brother Carlos Herrera, with whom he shares ideas and visions; to 
his fiancée, Luisa Fernanda Rodriguez, for her unconditional love, support, and encouragement, and; to his grandmother Aurora Flores, who taught him how to nurture plants, love, and respect nature.

\section{REFERENCES}

[1] PEMEX dona terrenos de la antigua refinería Reynosa para la construcción de un macro parque recreativo. gobierno del Estado de Tamaulipas, November 23, 2017. https:// www.tamaulipas.gob.mx/administracion/2017/11/ pemex-dona-terrenos-de-la-antiguarefineria-reynosa-para-la-construccion-de-un-macro-parque-recreativo/. Accessed 15 September 2019.

[2] Salinas Rivera, M. Historia de la primera refineria de Reynosa, El manana, 28 June, 2015. https://www.elmanana.com/historia-de-la-primera-refineria-de-reynosa-dfne-refineriade-reynosa-pemex-gimsa/2938925. Accessed 10 July 2020.

[3] Way, T. Landscapes of Industrial Excess: A Thick Sections Approach to Gas Works Park. Journal of Landscape Architecture 8, no. 1, 24 May 2013, pp. 28-39. https://doi. org/10.1080/18626033.2013.798920. Accessed 1 December 2019.

[4] Özkan, Ö. Strategic Way of Design in Rem Koolhaas' Parc de la Villette Project, thesis Graduate School of Natural and Applied Science of Middle East Technical University, 2008. Https://Etd.Lib.Metu.Edu.Tr/Upload/12610287/Index.Pdf. Accessed 25 July 2019.

[5] Le parc de la Villette a 35 ans: La grande aventure d'un projet d'avant-garde. Franceinfo : culture, 29 May, 2018. https://www.francetvinfo.fr/culture/patrimoine/histoire/leparc-de-la-villette-a-35-ans-la-grande-aventure-d-un-projet-d-avant garde_3334099. html. Accessed 27 August, 2020.

[6] Montanes Escalante, P., Garcia Barrios, L., \& Jimenez Osornio, J. Quarry Reclamation in Merida Yucatan Mexico: A Review on Achievements and Current Limitations. Tropical and Subtropical Agrosystems. vol. 5, no. 3, Universidad Autonoma de Yucatan. Yucatan, Mexico. 1 March 2005. http://citeseerx.ist.psu.edu/viewdoc/ download?doi=10.1.1.529.7321. Accessed 28 July 2020.

[7] Turney., G., \& Goerlitz., D. Organic Contamination of Ground Water at Gas Works Park, Seattle, Washington. Groundwater Monitoring and Remediation. August 1990. https://doi.org/10.1111/j.1745-6592.1990.tb00014.x. Accessed 05 July 2020.

[8] Sugden, E., The Adaptive Reuse of Industrial Heritage Buildings: A Multiple-Case Studies Approach. UWSpace. 2018. http://hdl.handle.net/10012/12823. Accessed 5 December 2019.

[9] Delgadillo Lopez, A.E., Gonzalez Ramirez, C.A., Garcia Prieto, F., Villagomez-Ibarra, J.R., Acevedo Sandoval, O., Phytoremediation: An Alternative to Eliminate Pollution. Tropical and Subtropical Agroecosystems, 10 January 2011. http://www.revista.ccba. uady.mx/ojs/index.php/TSA/article/view/814/565. Accessed 19 November 2019.

[10] Abdullahi, M.S. Soil Contamination, Remediation and Plants: Prospects and Challenges. Rehman Hakeem, K., Sabir, M., Ruhi Mermut, A. Soil Remediation and Plants. Elsevier Academic Press, Amsterdam, NL, 2014. https://www.sciencedirect.com/science/ article/pii/B9780127999371000188. Accessed 5 December 2019.

[11] Ramírez, V., Baez, A,. López, P., Bustillos, R., Villalobos, M., et al.,: Chromium HyperTolerant Bacillus Sp. MH778713 assists Phytoremediation of Heavy Metals by Mesquite Trees (Prosopis Laevigata). Frontiers in Microbiology. 13 August 2019. https://www. frontiersin.org/articles/10.3389/fmicb.2019.01833/full. Accessed 12 November 2019. 
[12] Garcia Villanueva, L., Fernandez Villagomez, G., Benzene and hydrocarbons profile from the soil light fraction of the environmental liability of the "18 de marzo" exrefinery, Mexico City. 2014. http://www.scielo.org.mx/scielo.php?script=sci_arttext\&p id=S0188-49992014000200007. Accessed 2020.

[13] Schjetnan, M., Sánchez, S. L. Mario Schjetnan: Reconciliar ciudad y naturaleza: GDU 40 años = reconciling city and nature: GDU 40 years. Ciudad de México, MX, 2017. Universidad Nacional Autonóma de Mexico, Facultad de Arquitectura. 